\title{
LA PSICOLOGÍA DE LOS SUEÑOS EN SOCIEDADES MINORITARIAS
}

\section{THE PSYCHOLOGY OF DREAMS IN MINORITY SOCIOCULTURAL GROUPS}

ROSA ELENA YÉPEZ ${ }^{1}$

Recibido: 15 de mayo de 2017 Aceptado: 29 de agosto de 2017

\footnotetext{
${ }^{1}$ Pontificia Universidad Católica del Ecuador, Facultad de Psicología, Quito, Ecuador (reyepez@puce.edu.ec / rostaelena@gmail.com).
} 



\title{
LA PSICOLOGÍA DE LOS SUEÑOS EN SOCIEDADES MINORITARIAS
}

\section{THE PSYCHOLOGY OF DREAMS IN MINORITY SOCIOCULTURAL GROUPS}

\author{
Rosa Elena Yépez
}

PALABRAS CLAVE: sueños, interpretación, significado, sociedades minoritarias KEY WORDS: dreams, interpretation, meaning, small societies

\section{RESUMEN}

¿Qué son los sueños? y ¿qué es soñar? Estas, como muchas otras relacionadas con este tema, son preguntas sin respuesta cierta, aunque topan un tema que ha provocado mucha inquietud en todas las sociedades y épocas de la humanidad.

Desde que se tiene conocimiento del ser humano y de su historia, se podría afirmar que las diferentes sociedades se han ocupado de interpretar los sueños también de diferentes maneras y que han adoptado diversas formas, momen- tos y circunstancias para relatarlos, para darles significado y para guiarse por ellos. Según los estudiosos las experiencias oníricas históricamente han tenido relación con la concepción del alma y del número de almas que puede tener un ser humano.

Este artículo ha dado importancia a autores clásicos desde el ámbito de los estudios psicológicos y antropológicos sobre los sueños, por lo que incluye relaciones a Freud y Jung, así como a Perrin y Lévi-Strauss. 
La autora de este artículo aporta con una clasificación general que incluye las interpretaciones de los sueños desde el ámbito psico-antropológico: Los sueños son un continuum de la vigilia, pueden tener interpretaciones: literales, de inversión, metafóricas directa e inversa, de analogías, contextuales, inter- textuales e intra-textuales, conforme los recuerdos de los sueños, las narraciones y análisis que de ellos hacen los mismos sujetos en tanto entes culturales. Todo esto en la comprensión que el ser humano es único en su esencia y diferente en su enfrentamiento a la realidad en que se desarrolla, es decir, en la cultura.

\section{ABSTRACT}

What are dreams? And what is to dream? These, like many related to this topic, are some unanswered questions, even though they deal an issue that has caused much concern in all societies and times of mankind.

Since you have knowledge of the human being and its history, it could be argued that societies have dealt with interpreting dreams also in different ways and have adopted various forms, times, and circumstances to relate dreams, to give them meaning, and to be guided by them. According to scholars dream experiences have historically had relationship with the conception of the soul and of the number of souls that can have any human being.

This article has given importance to classical authors from the field of the psychological and anthropological studies, so it includes relations to Freud and
Jung, as well as Perrin and Lévi-Strauss.

The author of this article contributes with a general classification that includes interpretations of dreams from the psycho-anthropological field. For example, dreams are the same thing that been awake; in the other hand, they can have literal, inverted, metaphoric, analogies, contextual, intertextual and intratextual interpretations, all of them according to their understanding of the narrations and analysis which of them make the same subject in both entities cultural. All this is on the understanding that the human being is unique in its essence and different in their confrontation to the reality that is developed, i.e., in their culture.

This article author has worked in a general classification that has dreams interpretation with psychology and anthropology view. 


\section{INTRODUCCIÓN}

Los sueños, se relacionan con el inconsciente, tanto individual como colectivo. Por lo tanto, su acercamiento permite un conocimiento del ser humano, por lo que se ha decidido la redacción de este artículo, que conlleva también el afán de crear inquietud sobre este tema en estudiantes y profesores, principalmente de las ciencias humanas, al intentar conjugar acercamientos desde los ámbitos de la Psicología y la Antropología.

Se inicia el trabajo con la definición de lo que es soñar y lo que son los sueños. Luego se hace referencia a importantes personajes que, desde el ámbito estudiado por la Psicología y el Psicoanálisis, han aportado con sus estudios sobre este tema: Sigmund Freud y Carl Jung, quienes han servido de guía hasta la actualidad para los estudiosos de este tema.
El presente artículo contiene también relatos de los sueños en sociedades socio-culturales minoritarias de América, referidas por articulistas investigadores que han compilado la narración de este fenómeno; también se ha incluido la propuesta de un autor importante desde la Antropología, Michel Perrin, así como una relación breve al Antropólogo estructuralista Claude Lévi-Strauss. Según puede desprenderse de todos los estudios mencionados, la interpretación de los sueños desde el ámbito cultural ayudaría a los individuos y a los grupos a mantener el equilibrio y a disminuir ansiedades.

Se presenta, además, una clasificación de la interpretación de los sueños desde las comunidades referidas, que sintetiza la gran variedad de formas simbólicas de representación y de vida, para concluir en la similitud del espíritu humano y su diferencia cultural.

\section{LOS SUEÑOS: DEFINICIÓN}

Es probable que todo ser humano, alguna vez por lo menos, se haya preguntado sobre los sueños, lo que recuerda o lo que no recuerda de su propia experiencia onírica. Es fácil dejarse atrapar por el relato de un sueño raro, hermoso o terrorífico, pues del sueño sur- gen relatos e infinidad de inquietudes, por lo que este tema se vuelve fascinante y de amplio y diverso acercamiento.

Es de común interés conocer qué sucede cuando se duerme; al respecto, Delacroix afirma: "El primer resultado del sueño es el eclipse por lo menos parcial 
de las relaciones sensitivo-motoras con el medio, por relajamiento del tono muscular, ausencia de la relatividad, elevación de los umbrales sensoriales; como también el descenso de nivel mental" (394)

No es lo mismo decir "tengo sueño", alusión a las ganas, deseos o necesidad de dormir, que referirse al sueño como el fenómeno que se produce cuando alguien duerme; el sueño sigue siendo de difícil definición, la que va a depender, en gran parte, de qué disciplina enfoque el fenómeno, hecho, cosa en cuestión.

Sin embargo, en algo que todos podemos concordar es en que los sueños han inquietado a toda la humanidad, sin fronteras geográficas ni temporales; se han explicado e interpretado de diferentes formas, y han tenido diferentes aplicaciones. Hay personas que recuerdan comúnmente lo soñado y otros que comúnmente olvidan sus sueños; muchas veces nos causan extrañeza o miedo, nos abruman por su fuerza o su belleza; ellos nos remiten a situaciones que rompen con todo esquema; incluso provocan cuestionamientos de si los sueños fueron tales, o son imaginación o recuerdo.

El verbo soñar, para la Real Academia Española (RAE) es representarse en la fantasía imágenes o sucesos mientras se duerme. Esto hace que los sueños sean únicos y particulares al soñador, no pueden otras personas ser testigos de los mismos; ni siquiera el soñante puede tener acceso a sus propios sueños, toda vez que son sucesos pasados y de los que no se tiene conciencia en el momento en que suceden.

En este artículo se aborda este tema pasando brevemente por el Psicoanálisis y la Psicología Jungiana, para llegar al punto de vista de otra ciencia humana, la Antropología. Como es de suponerse, el tratamiento y las afirmaciones alrededor de los sueños dependerán de la teoría que cobija el tema y, por tanto, de su acercamiento al mismo y a los soñantes. 


\section{ACERCAMIENTO A LOS SUEÑOS DESDE FREUD Y JUNG}

Sigmund Freud (1856-1939) y Carl Gustav Jung (1875-1961) como precursores del psicoanálisis, no pasaron por alto el material onírico como un elemento producto del inconsciente.

Freud, en su obra: "La interpretación de los sueños" propone la producción onírica como la realización alucinatoria de deseos, dado que el sueño es producto y manifestación del inconsciente del sujeto. Al ser entonces exquisito en material inconsciente, el sueño despertó el interés de Freud, quien propone que todo sueño es interpretable, aun cuando este material esté deformado o disfrazado; para su interpretación plantea mecanismos que hay que tomar en cuenta, como la condensación, el desplazamiento, la simbolización, la elaboración secundaria.

La condensación de varias ideas latentes se da cuando los contenidos manifiestos de varias ideas se funden en una sola, especialmente sucede cuando en el sueño hay palabras.

El desplazamiento consiste en la representación de una idea latente con otros o en otros contenidos manifiestos, puede así aparentemente variar la intensidad del valor psíquico de este evento.

El tercer mecanismo, la simbolización, es el empleo de un símbolo para expresar el contenido latente. Freud pro- pone que estos símbolos (los oníricos) son individuales y que no tienen un significado fijo o rígido, porque dependen de la individualidad del sujeto.

El cuarto mecanismo propuesto por Freud es la elaboración secundaria, que intenta disfrazar el contenido "en bruto" del sueño con una apariencia lógica y coherente, por lo que este mecanismo es el que puede ser narrado por el soñador/sujeto.

En la Psicología Analítica de Jung, los sueños ni esconden ni disfrazan; no los entendemos por nuestra incapacidad frente al lenguaje simbólico que ellos utilizan; aunque son un producto espontáneo y útil del inconsciente, para cuya interpretación se emplearían principalmente dos perspectivas; la primera que tendría relación con la causa del sueño y, sobre todo, con el propósito del mismo, que podría entenderse como un intento de la psique para solucionar un problema; la segunda perspectiva estaría relacionada con la compensación de la psique ante situaciones conscientes que está viviendo el individuo.

Jung mantiene esta lógica del sueño como la producción de contenidos en una suerte de dinámica entre consciente e inconsciente; a partir de eso, plantea que estos contenidos, de manera autónoma, fluctúan entre el 
consciente y el inconsciente y tienen la libertad de disminuir su intensidad; Jung llama a este mecanismo supresión; gracias a este se produce la capacidad de creación simbólica e imágenes de forma autónoma y, por lo tanto, existe la posibilidad de autocuración. Esa autonomía es la que permite que el contenido de los complejos afectivos se haga consciente o inconsciente y eso es lo que produce la perturbación del sujeto; la supresión sería, para Jung "un arquitecto del sueño".

Para el mismo autor el material psíquico pertenece al reino del inconsciente, pero en este no hay solo elementos del pasado, sino el "germen de la nueva vida", es decir la capacidad de la creación de los nuevos símbolos, imágenes e ideas, que nunca fueron conscientes pero que forman parte integral del crecimiento de todo ser humano. De ahí que el inconsciente sea, entonces, el reservorio de la imaginación.

A breves rasgos lo dicho sobre Jung explicaría, de alguna forma, la importancia emotiva que tiene para el soñador la cotidianidad, aunque sus muros racionales no permitan el contacto con la real intensidad de las emociones, lo que produciría la imagen onírica sobre la que se debe poner atención. La tarea de restituir el equilibrio psíquico, es decir equilibrio entre el consciente y el inconsciente de un individuo co- mún, "... se puede conseguir mediante los modos de vivir naturales, las objeciones fundadas en la razón, la fortificación de la voluntad, hasta el análisis de lo inconsciente" (García).

Jung afirma:

Un estrato en cierto modo superficial de lo inconsciente es, sin duda, personal. Lo llamamos inconsciente personal. Pero ese estrato descansa sobre otro más profundo que no se origina en la experiencia y la adquisición personal, sino que es innato: lo llamado inconsciente colectivo... he elegido la expresión 'colectivo' porque ese inconsciente no es de naturaleza individual sino universal... es idéntica a sí misma en todos los hombres y constituye así un fundamento anímico de naturaleza supra-personal existente en todo hombre $(1970,10)$.

Este inconsciente, relacionado con el hombre primitivo (con mitos y leyendas, por ejemplo), según lo diría Jung, ya no sería contenido inconsciente, sino que se ha transformado en fórmulas conscientes, trasmitidas de contenidos originalmente profundos de lo inconsciente. En el contenido de la interpretación de los sueños de las sociedades minoritarias seleccionadas para este artículo, podría deducirse este planteamiento jungiano.

En definitiva, la teoría jungiana sobre la interpretación de los sueños 
facilitaría la comprensión de las interpretaciones culturales de los mismos, conforme lo recalca Ursula Oberst, pues su contenido simbólico, como lo diría Jung, sería: ".. la propuesta de solución de un conflicto. De esta manera, los sueños pueden ayudar, de forma simbólica, a la mente consciente a preparar un camino que ya está dibujado".

A continuación se presenta la propuesta derivada de los relatos de los sueños de sociedades con culturas milenarias, que superviven en el continente americano.

\section{LOS SUEÑOS DESDE LA ANTROPOLOGÍA}

La antropología también es una disciplina interesada en este tema, especialmente en la mirada de estudiosos con enfoque psicologista; ellos coincidirían en lo básico sobre los sueños, que no puede ser negado por antropólogos, ni psicólogos, pues los sueños constituirían una serie de fenómenos psicológicos que se producen cuando las personas duermen, que no siempre se recuerdan y que, como lo afirma Valéry, son fenómenos que "observamos" solo cuando están ausentes.

Entre las críticas desde un enfoque disciplinario de las ciencias sociales, dirigidas al enfoque freudiano, está aquella que apunta a la universalidad del sueño afirmada por el psicoanálisis, se funda sobre una simple observación: en numerosas sociedades las prácticas sexuales, sean estas juzgadas normales o aberrantes, son frecuentemente soñadas y más a menudo aún, traducidas por las claves de los sueños en comportamientos sociales comunes. Esto sucede, por ejemplo, entre los Guajiro' al referirse a determinado sueño: "'Si... vos os juntáis con una joven en un sueño, seréis enterrado en una tumba nueva en vuestra muerte'... Ahora bien, una exageración del psicoanálisis afirmaría una tendencia inversa: la interpretación de los sueños en términos de sexualidad reprimida." (Perrin, Les Praticiens du rêve,12).

Una crítica más general ha sido expuesta por el antropólogo Claude Lévi-Strauss, para quien

...los elementos incoherentes (del sueño) se presentan al subconsciente de la persona que duerme como las piezas esparcidas de un rompecabezas a las cuales, para apaciguar la perturbación intelectual suscitada por su heterogeneidad deberá, con esa forma de

\footnotetext{
1. M. Perrin. Op. cit.
} 
bricolage que es también el trabajo del sueño, si no darles una coherencia (...) al menos someterlos a un esbozo de organización (Lévi-Strauss, 257).

Lévi-Strauss añade una idea freudiana importante para esa misma crítica:

... El verdadero motor de la formación de un sueño, escribe Freud, obedece regularmente a la realización de un deseo. Pero antes que el deseo, que de por sí es una noción confusa, se sitúa el apetito o la necesidad; y la necesidad universal que se juega en el trabajo del sueño, al contrario de lo que Freud a veces parece creer, es el de someter los términos surgidos en la incoherencia, a una disciplina gramatical (ibid).

Con todo esto, desde la Antropología, podría afirmarse que todo lo relativo a los sueños dependerá, en gran medida, de la cultura en la que se experimentan.

\subsection{Los sueños conforme las diferentes sociedades}

En este punto se relatarán brevemente los enfoques de los sueños desde sociedades minoritarias de América, en otras palabras, desde sociedades que permanecen en contacto con las citadinas occidentales o con gran influencia occidental; aquellas que se niegan a ignorar sus concepciones culturales ancestrales, especialmente las relacionadas con sus creencias y manifestaciones ideológicas. Con esto se podrá constatar las diferencias culturales en las experiencias oníricas, su interpretación y acciones surgidas de estas.

En varias de estas sociedades no se concibe una separación entre el sueño y la vigilia, sus miembros establecen una "continuidad". Tal es el caso de los indios beaver o también conocidos como dunne-za (Canadá), entre los cuales el estudio de los sueños sugiere que estos y la vigilia son mundos no separados y que, más bien, se sobreponen; el cazador provoca una especie de consulta a los sueños, pues estudia la tecnología de la caza a través de ellos.

En esta sociedad, desde el enfoque de la autora de este artículo, se evidencian las inquietudes y necesidades más básicas de los beaver, enfrentadas con la continuidad del sueño y la vigilia, dos momentos que forman parte de su realidad y que no tienen diferencia. Ahí, la continuidad justificaría el quehacer del cazador y sus decisiones respecto a cuándo, dónde, cómo cazar.

Entre los sioux lakota (Canadá), estudiados por Vaseilles, en "Antropología y Experiencias del Sueño" hay, con los sueños y visiones, "encuentros" con los espíritus; estos anuncian enfermedades y explicarían comportamientos nuevos como la práctica de la prostitución en hombres y mujeres y los prófugos de la justicia, en una especie de justificación 
social a fenómenos que comúnmente habrían sido tabú en épocas de un pasado reciente. Así, a criterio de la autora de este escrito, se estaría permitiendo, o mejor creando, una excusa o aceptación social de lo que considera esta sociedad inevitable, dado el contacto con la sociedad mayoritaria y dominante, lo que permitiría afirmar la "acomodación" de las imágenes arquetípicas a las necesidades de sobrevivencia de la sociedad sioux.

Los otomíes, descendientes de los mayas, parecerían acercarse a la interpretación desde una concepción binaria: masculino-femenino, arriba-abajo, duro-suave, lleno-vacío, etc., para confluir en un principio de inversión; por ejemplo, si se sueña en alguien que va a morir, en realidad esta persona sanará, en una especie de lo que Ilama Galinier "ley de antítesis generalizada". Sin embargo, en el seno de esta sociedad, no todo puede tener el mismo tratamiento; así, hay principios de causalidad directa en sueños referentes a alimentación y animales.

En todo caso, los sueños tienen dos contenidos: el uno explícito y el otro implícito, que es el auténtico y es analizado con la ayuda de una especie de clave local, comúnmente interpretada por los sabios (Galinier, ibid). En esta sociedad también se da, entonces, respuesta a las necesidades psico-sociales al suavizar las interpretaciones pesimistas o que pudieran conllevar mayor sufrimiento.
Michel Perrin, quien realizara estudios bastos de los sueños, refiere aquellos de los guajiro, con su lógica de interpretación que, teóricamente, producen una filtración radical; reducen, o tal vez sea mejor afirmar que relacionan el infortunio a motivos como violencia interlineal, muerte de personas muy cercanas, enfermedades, accidentes, adulterio de las mujeres. Para esta cultura los mensajes implican el cuerpo y relaciones entre los sexos, con una delicadeza de interpretación que permite incorporar temas sexuales en las conversaciones, sin ofender las conveniencias sociales.

Relacionadas con sus sueños, con un esquema complicado de interpretación, es posible encontrar las siguientes claves: analogías simples (cortar leña puede devenir en rotura de una pierna); analogías dobles (lluvia = entierro, porque se derramarán lágrimas, la fuerza de la lluvia es proporcional a la abundancia de lágrimas); inversión (amar a alguien significa que esa persona no lo amará) y universales (orinar, defecar o perder un diente = muerte de alguien cercano). Sin embargo, y como sucede en probablemente todos los casos sociales de interpretación de los sueños, se intentará, con la prudencia necesaria, calmar o al menos mitigar la angustia producida por un sueño que podría relacionarse con un mal presagio (Perrin, ibid). 
La interpretación de los sueños y su uso son diferentes en todas las culturas. En efecto, mientras en unas los sueños son mandatorios, en otras son sugerentes. Hay extremos en los mandatorios, como el caso de los mapuche de Chile. Su interpretación es conducida por los soñadores individuales de cada familia, y cuando ellos no pueden cumplir con esta necesidad, acuden a los shamanes; esto especialmente cuando hay acontecimientos importantes en un futuro próximo.

Los análisis especializados Ilevan gran complejidad, es decir que la interpretación remite a análisis intratextuales, intertextuales, y contextuales. Para ejemplificar esto se puede recurrir al caso de un joven al que se llama Pablo en el artículo de Degarrod, quien estudió los sueños entre los mapuche de Chile.

Pablo tenía pesadillas y terrores nocturnos; en la explicación del autor, la madre de Pablo tuvo un sueño en que tomó para comer la fruta de un árbol ajeno; el mitranalwe, dueño del árbol, pidió que le pagaran por esa fruta, mas eso no se pudo cumplir. Luego de este sueño, el padre de Pablo soñaba que el mitranalwe pedía la paga con sacos de harina, lo cual se cumplía esporádicamente en los sueños del padre de Pablo; este se convirtió, consecuentemente, en una especie de chivo expiatorio de la falta de su madre.
Para disminuir la culpabilidad y el pronóstico a futuro, parecería que el pago que se está haciendo al mitranalwe por la fruta robada en el sueño podría permitir la mejora de Pablo. En este caso se puede deducir que la responsabilidad y la vida del sujeto están insertas en las de su familia, lo que disminuiría la ansiedad de la misma familia y del sujeto soñador. Aun así, en las últimas noticias de Pablo, relacionadas en el mismo artículo; este refiere sueños en que ve a su hermano muerto, quien lo está llamando; a su decir esto significaría que morirá pronto.

Entre los épera, cuya sociedad se asienta en la costa norte ecuatoriana, las claves de interpretación pueden variar entre metafórica directa (deslave = entierro), y metafórica inversa (si sueña que se va a casar es que no lo hará); se utiliza también la interpretación llamada universal, que refiere por ejemplo a la muerte o enfermedad de alguien cercano si se sueña en caída de piezas dentales.

Aun así, en esta sociedad los sueños son sugerentes y muchas veces deben ser consultados con personas conocedoras de la misma cultura, aunque lejanas. Es probable que estas acciones y formas de concepción del sueño y su interpretación sean consecuencia, según la autora de este artículo, de la necesidad de los individuos de esta cultura de continuar su relación con la sociedad épera mayor, que se asienta en Colombia. 
Los sueños de los zápara, cultura ecuatoriana prácticamente extinta, cuyos poquísimos integrantes se han unido a los quichua para sobrevivir, han sido estudiados por Bilhaut Anne-Gael quien, en su tesis de doctorado publicada por Abya-Yala, afirma que los zápara consideran como de su patrimonio su propia manera de soñar y de ver los objetos.

Los sueños son para ellos fuentes de saberes y permiten tener un aprendizaje visual personal que incluso lleva a una especie de teorías personales, por lo que los sueños no se confrontan. Los sueños, en esta sociedad, a mi entender, probablemente sirvan para aliviar la tensión de una sociedad que está extinguiéndose de forma muy acelerada y que constituyan un último recurso de identidad y sobrevivencia cultural.

Puede decirse de los sueños que, en la mayoría de sociedades, son concebidos como fenómenos que se suceden en tiempos y distancias diferentes a las que gobiernan la vigilia. Por ejemplo para los raramuri de México (llamados también taraumara), el sueño debe comprenderse inseparable de la distancia, pues los seres del mundo de los sueños, es decir del otro mundo, existen únicamente en la noche y en lugares muy lejanos; por ellos viajan las almas, pues ellas tienen la cualidad infinitamente rápida de movilidad.

En muchas sociedades el chamán "se hace" por mandato o insinuación oní- rica, y es el especialista en la interpretación de los sueños, particularmente cuando estos no tienen una interpretación común clara; en otras sociedades, ligadas más a la concepción occidental, los sueños sirven para interpretar el inconsciente individual y colectivo. En todo caso, las "claves" de los sueños vendrían a ser, entonces, el producto de una práctica de filtro social, derivada de la sabiduría compartida y funcional a las necesidades culturales.

\subsection{Lógica de interpretación de los sueños}

La tendencia temática de los sueños parece estar claramente vinculada con la concepción cultural sobre la persona y la propia sociedad. Como ya se ha dicho, conforme las particularidades culturales, por tanto también ideológicas, de las diferentes sociedades, la persona puede estar compuesta de varias almas, o de una sola. "Por ejemplo, un pueblo que atribuye al alma una gran autonomía, narrará el sueño en tercera persona..." (Perrin, 1990, 8).

Concebir varias almas equivaldría a una representación más compleja de la persona, lo cual permitiría una mejor explicación de las experiencias vividas. Los Mehinaku del Brasil distinguen tres almas, separando así, enfermedad, muerte y sueño (Gregor, referido por Perrin, 1990). Similar concepción sobre varias 
almas se tiene en algunas sociedades selváticas de Sudamérica, como entre los shuar (que comparten territorio ecuatoriano y peruano).

Las distintas concepciones sobre las almas se verán reflejadas en los sueños y su tratamiento, así como en su narración y las acciones que les siguen; así, quienes tienen una sola alma comúnmente narran sus sueños en primera persona, aquellos que tienen dos los narrarán en tercera persona. Además, como el sueño, en general, es concebido como el desprendimiento del alma, su regreso marcará la vida y su no regreso la muerte; en el medio estará la enfermedad, causada por la ausencia temporal de la misma.

Otra diferencia cultural está dada por la concepción general del sueño; todas las culturas minoritarias les dan importancia primordial; sin embargo, hay unas que los conciben como un continuum de la vigilia, otras que los consideran avisos de lo que vendrá, y otras que deben hacer un esfuerzo interpretativo para actuar acorde con lo que están evidenciando los sueños.

Con lo dicho, se puede afirmar la diversidad cultural de los sueños y sus interpretaciones, así como la universalidad de este fenómeno y la importancia individual y social que surgen de él. Las interpretaciones, según se propone en este trabajo, derivadas del análisis cultu- ral, pueden variar entre una, varias o todas las siguientes posibilidades:

a. Tratamiento de los sueños como un continuum de la vigilia

b. Interpretación literal

c. Principio de inversión

d. Interpretación metafórica directa

e. Analogías dobles

f. Interpretación metafórica inversa

g. Interpretación metafórica compleja

h. Interpretación contextual

i. Interpretación intertextual

j. Interpretación intratextual.

A continuación se hará una breve explicación de cada opción.

a. Los sueños son un continuum de la vigilia: esta postura existe en varias sociedades minoritarias, una de las cuales ya se tomó en cuenta, la de los Beaver (Canadá). En esta cultura, las sendas de su sueño indican las sendas del mundo físico, el animal que cazarán ya lo habían visto en su sueño.

b. Interpretación literal: En sociedades donde hay este tipo de interpretación, cuando se sueña en caza es que se va a cazar, si se sueña en lluvia va a llover, etc. Se podría asumir como una forma de interpretación literal el siguiente relato de los Pilaga (Chaco Central de Argentina), 
entre quienes no se hace ruptura alguna entre la vida de la vigilia y la de los sueños, como se puede concluir del siguiente relato: "Anoche cuando pasaba cerca de la casa de Sayté, salió y me dijo que le diera plata; yo le expliqué que no tenía, pero esta mañana (de tanto caminar) me dolía el cuerpo, todavía el estómago me molesta" (Idoyaga, en Antropología y Experiencias del Sueño, 199).

c. Principio de inversión: los guajiro se permiten también esta clase de interpretación, por ejemplo si se sueña en dinero significa que no lo tendrá en realidad; si se sueña que alguien ama al soñante significa que en realidad no lo hará.

d. Interpretación metafórica directa o analogía simple: cuando la sociedad interpreta con correspondencias visuales, sonoras, verbales, etc., aquello que alguien ha soñado. Ejemplo también de esta interpretación la dan los guajiro, cuando "Si uno sueña que está pintado con pasta de bija quiere decir que será herido, ya que ... 'los dibujos lineales que se hacen con esta pasta en el rostro son rojos como la sangre... "' (Perrin, 82), o cuando sueñan que se corta leña y significa la fractura de un miembro.

e. Analogías dobles: También puede verse un ejemplo guajiro. Para ellos si se sueña con lluvia alguien morirá, pues allí se llorará y la fuerza de la Iluvia indicará la abundancia de lágrimas y la cantidad de gente que asistirá a los funerales.

f. Interpretación metafórica inversa o antítesis generalizada: el caso de los mapuche de Chile nos puede ilustrar esta posibilidad de interpretación y acciones futuras. Tal es el caso de una joven, quien se embarazó de un hombre con solvencia económica, en sus meses de gestación ella soñaba a su bebé, lo que le producía gran felicidad; esta mujer relató su sueño a la machi (shamana) y esta le dijo que estaba embarazada de un espíritu maligno y que debía abortarlo; en efecto, esta joven se practicó un aborto. Continuó soñando al niño y esto la llenaba de temor porque se interpretaron estos sueños en el sentido en que ella estaba siendo tentada por un espíritu maligno; tiene temor de empezar a criar, en sus sueños, a este espíritu. (Degarrod, en Antropología y Experiencias del Sueño)

g. Interpretación metafórica compleja, llamada homología por Perrin (85): Los mismos guajiro, en determinadas circunstancias, hacen interpretaciones complejas; por ejemplo si alguien sueña que tiene cabellos largos tendrá una tumba mal cuida- 
da luego de morir; la interpretación relaciona: "cabellos" es a "cabeza", como "hierbas" es a "tumba".

h. Interpretación contextual: Es la que se asimilaría al primer acercamiento en ciudades con influencia de la Psicología. En este tipo de interpretación se toman en cuenta las circunstancias que están presentes cuando un individuo sueña. Tal es el caso de Pablo, ya indicado en la cultura mapuche, quien sueña que su hermano muerto lo llama; para Pablo, eso es un aviso de su muerte próxima y su descanso de los espíritus que lo han atormentado.

i. Interpretación intertextual: También pueden ejemplificarse con los sueños de Pablo, pues su familia interviene tanto en su enfermedad, como en su tratamiento, a través de sus sue- ños e interpretaciones. Así, el padre está pagando por medio de ellos la deuda al espíritu mitranalwe.

j. Interpretación intratextual: En los mapuche, también el caso de Pablo ejemplifica esta interpretación, cuando los sueños de sus padres se relacionan entre ellos, la madre robó la fruta de mitranalwe, el padre está pagando la deuda. Además, como lo explica el texto onírico de Pablo, estos sueños y su desgracia se deben a una tía paterna que maldijo a la familia y a él a causa de problemas por herencias.

Una vez presentado un planteamiento de clasificación de los sueños y sus interpretaciones desde las culturas y sociedades nombradas, a continuación de presentan algunas conclusiones.

\section{CONCLUSIONES}

En la psicología y en la antropología los sueños son importantes para la comprensión del ser humano; ambas disciplinas coinciden en que los sueños dicen algo sobre el soñante y, por tanto, pueden ser analizados o interpretados a la luz del contexto, individual en unos casos, colectivo en otros. Por lo mismo, más que mirar un distanciamiento se puede decir que hay coincidencias en lo que ellas persiguen.

Como se desprende de este artículo, los miembros de las diferentes sociedades tienen infinitas posibilidades de soñar, acordes estas con la propia cultura; por tanto, todo alrededor de los sueños es diferente: sobre qué sueñan, cuándo es imprescindible contar un sueño, a quién cuentan los sueños, cómo se interpretan, qué hacer con esa interpretación. 
En consecuencia, podría afirmarse que cada una de las culturas presentadas en este artículo interpretan los sueños conforme las necesidades sociales e individuales resultado de su concepción cultural. En el caso de las sociedades minoritarias de América, tomadas para el presente trabajo, se confirma que cada una tiene no solo temáticas relacionadas con su cultura, sino que tienen "algo que decir al soñador", como respuestas a sus necesidades básicas como: alimentación, reproducción, relaciones familiares, contactos con individuos de su misma u otras culturas y que han tenido un papel importante en la vida del soñador.

Interesante resulta evidenciar que en todas estas culturas, los interpretantes de los sueños, cualesquiera que sean, son un factor muy importante para decisiones a futuro y que, en todos los casos, tratan de disminuir ansiedades y solucionar conflictos.

La teoría jungiana facilita la comprensión de las temáticas e interpretaciones de los sueños de las sociedades minoritarias tratadas en este artículo, pues su aplicación confirmaría la estrecha relación existente entre los contenidos de los sueños y las acciones culturalmente pautadas, derivadas de esa interpreta- ción cultural, para buscar soluciones a los conflictos tanto individuales como colectivos y para tomar decisiones.

En el mundo hay una diversidad extraordinaria en la concepción de la vida y la muerte, del cuerpo y del alma, que dice y demuestra que los seres humanos ameritan diversos caminos para su comprensión y que todos esos caminos, deben ser respetados y considerados como una riqueza.

Todas las disciplinas relacionadas con el ser humano deben tomar en cuenta las especificidades y particularidades de quienes están tratando de comprender, pues de lo contrario se estaría ignorando la realidad. Esta es una responsabilidad compartida.

Las diferencias en la forma de los sueños y en sus interpretaciones nos recuerdan también las coincidencias del ser humano en sus necesidades, incluidas las básicas, es decir las relacionadas con la supervivencia: alimentación, cobijo, la salud, así como las del ser humano necesitado de explicaciones, de justificaciones, de razones para la vida, para responder preguntas trascendentes. Si bien todos los seres humanos compartimos la misma esencia, la cultura ofrece la gran riqueza de la diversidad. 


\section{BIBLIOGRAFIA}

Delacroix, H. (s.f.) Le reve, en el Nouveun Taité de Psychologie, publicado bajo la dirección de G. Dumas: Diccionario Filosófico

García, M. (2016). La Magia de los Sueños. Recuperado de: http://www. sowelu.cl/blog/2016/05/la-magia-los-suenos/

Jung, Carl G. (1970). Arquetipos e Inconsciente Colectivo. Recuperado de http://www.formarselibros.com. ar/libros-Jung/1_pdfsam_JungCarlGustavArquetiposEInconscienteColectivo.pdf

Lévi-Strauss, Claude (1985). La Polière jalouse. París: Plon.

Oberst, Ursula ( ). La Teoría de los Sueños de Carl Gustav Jung. Recuperado de www.oberst.es/documentos/junguiana.pdf

Perrin, Michel (coordinador) (1990). Antropología y Experiencias del Sueño. Abya-Yala Quito.

Perrin, Michel. Les Praticiens du rêve, París, PUF, 1992

Alonso, Juan (2004). La Psicología Analítica de Jung y sus aportes a la Psicoterapia. Recuperado de http:// sparta.javeriana.edu.co/psicologia/publicaciones/actualizarrevista/archivos/N3N106la_psicologia.pdf
Alonso G., Juan Carlos, La Psicología Analítica de Jung y sus aportes a la psicoterapia Universitas Psychologica [en linea] 2004, 3 (enero-junio. Recuperado de: <http://www.redalyc.org/articulo.oa?id=64730107> ISSN 16579267

http://revistadigitaldepsicoanalisis. blogspot.com/2011_06_01_archive.html

http://www.significadodelossuenos. com.es/jung-y-la-interpretacionde-los-suenos/

Bilhaut, Anne-Gael. (2011) El sueño de los záparas. Patrimonio onírico de un pueblo de la Alta Amazonía. Quito: Abya-Yala

Bruner, E. (1989). Dreaming: Anthropological and Psychological Interpretations. American Etnologist. Recuperado de http://onlinelibrary.wiley.com/doi/10.1525/ ae.1989.16.3.02a00460/full

Cevallos Juan y Crespo Janett (2014) Los sueños y los mensajes culturales. Estudio de caso, comunidad Santa Rosa de los Épera. Disertación para el título de Psicólogo Clínico. Quito: PUCE, 2015. Recuperado de http://repositorio.puce.edu.ec/ handle/22000/8480 
Freud, Sigmond. (2016) La interpretación de los sueños. Recuperado de http://www.alejandriadigital. com/2016/01/11/la-interpretacion-de-los-suenos-de-freud-enpdf-502-paginas-obra-de-dominio-publico-descarga-gratuita/ http://onlinelibrary.wiley.com/ doi/10.1525/ae.1989.16.3.02a00460/ full
Perrin, Michel. (2013). El poder de los sueños. Original: La puissance des rêves. Traducción: López Arjona, Ana (2016). 
